Article

\title{
Decontaminating Terrestrial Oil Spills: A Comparative Assessment of Dog Fur, Human Hair, Peat Moss and Polypropylene Sorbents
}

\author{
Megan L. Murray *, Soeren M. Poulsen and Brad R. Murray ${ }^{\mathbb{D}}$ \\ School of Life Sciences, University of Technology Sydney, PO Box 123, Sydney, NSW 2007, Australia; \\ SorenMargaard.Poulsen@alumni.uts.edu.au (S.M.P.); brad.murray@uts.edu.au (B.R.M.) \\ * Correspondence: Megan.Murray@uts.edu.au
}

Received: 4 June 2020; Accepted: 4 July 2020; Published: 8 July 2020

\begin{abstract}
Terrestrial oil spills have severe and continuing consequences for human communities and the natural environment. Sorbent materials are considered to be a first line of defense method for directly extracting oil from spills and preventing further contaminant spread, but little is known on the performance of sorbent products in terrestrial environments. Dog fur and human hair sorbent products were compared to peat moss and polypropylene sorbent to examine their relative effectiveness in adsorbing crude oil from different terrestrial surfaces. Crude oil spills were simulated using standardized microcosm experiments, and contaminant adsorbency was measured as percentage of crude oil removed from the original spilled quantity. Sustainable-origin absorbents made from dog fur and human hair were equally effective to polypropylene in extracting crude oil from nonand semi-porous land surfaces, with recycled dog fur products and loose-form hair showing a slight advantage over other sorbent types. In a sandy terrestrial environment, polypropylene sorbent was significantly better at adsorbing spilled crude oil than all other tested products.
\end{abstract}

Keywords: crude oil; petroleum contamination; disaster management; land pollution

\section{Introduction}

Crude oils are complex in composition and form the basis of many materials and fuels in high demand by global communities [1]. When crude oil spills occur, they often cause acute and persistent damage to the impacted environments, with lethal or sub-lethal consequences for plant, animal, and microbial communities, as well as human settlements [2-4]. The immediate health impacts of spilled oil on animals include cancers, organ function disruptions, internal bleeding, brain lesions, dehydration, loss of body weight, suffocation via smothering and increased population mortality rates $[5,6]$. Chronic dangers of spilled oil on individuals include reduced metabolic rates, altered behaviors, stunted growth patterns and impaired infant development $[7,8]$. The lingering after-effects of oil spills on whole populations also include changes in migration, competition behaviors and decreased species abundance $[9,10]$.

Terrestrial oil spills are particularly hazardous, if untreated, as they can contaminate soils and sediments and persist in harmful effects for many decades [11]. Furthermore, crude oil from terrestrial spills can leach into groundwater and other fresh water sources, spreading further across the landscape and causing severe damage to surrounding ecosystems [12]. It is therefore imperative to rapidly respond with effective solutions once terrestrial oil spills occur in order to prevent significant and lasting ecological damage [13].

Current methods for the immediate treatment of terrestrial oil spills include the use of trenches, manual recovery through mechanical excavation, exclusion booms, and different types of sorbent 
materials (i.e., deployed as booms and padding). These methods have been reported as effective in large scale events; however, they can be very expensive to utilize, and may not be uniformly suitable for diverse terrestrial surfaces [14-16]. Furthermore, direct comparisons of oil-remediation methods to quantify which is the most effective are rare. For marine and freshwater environments, sorbents are an effective and popular choice for disaster response teams and have been used extensively over the last few decades in efforts to remediate affected sites [17]. These sorbents are normally applied as sheets or as booms directly upon the surface layer of the crude oil in attempts to contain and absorb the oil. Synthetic sorbents like polypropylene are a popular material for oil spill sorbents due it its oleophilic and hydrophobic properties and high buoyance, making it useful for aquatic sites [18]. However, recent research has suggested that natural-origin and recycled materials such as human hair waste, recycled sulfur polymers, dog fur clippings, and peat moss are beneficial in extracting oil due to their natural absorbance, low value and easy biodegradability $[17,19-21]$. Booms made of recycled human hair waste were significantly better at adsorbing crude oil from simulated oceanic spills compared to mainstream commercial sorbents including polypropylene, recycled cellulose, and cotton by-products [17]. No research to date has comparatively investigated the decontamination of crude oil from terrestrial surfaces using standardized sustainable-origin sorbents, including recycled human hair and dog fur.

The central aims of this study are to assess the crude oil adsorbance effectiveness of eight different sorbents within a comparative framework, including controlled microcosm environments; to quantify whether sustainable-origin products perform as well at adsorbing crude oil as polypropylene; and to determine if crude oil decontamination is influenced by the terrestrial environments the sorbents are deployed upon.

\section{Materials and Methods}

\subsection{Sorbent Materials}

The sorbents tested included two commercially available products (i.e., polypropylene and peat moss) as well as sustainable-origin prototypes including felted mats comprised of dog fur and human hair, and prototype oil spill sorbent booms filled with dog fur and human hair (Table 1). The sustainable-origin sorbents were sourced from Matter of Trust (USA) and Sustainable Salons (Australia). Matter of Trust is a not-for-profit organization that produces sustainable-origin textiles for environmental applications, including felted mats. Although primary textile for the organization is recycled human hair, during the 2007 Cosco Busan disaster, the organization used recycled dog fur for oil spill decontamination. Similarly, following the 2010 Deepwater Horizon disaster, the organization deployed human hair-filled sorbent booms to adsorb oil that washed onto beaches of the southern states of America. Sustainable Salons is an Australian-Pacific based company which recycles various salon waste products and dog grooming wastes into sustainable-origin products, including oil spill booms. Each sorbent product tested was standardized to $10 \mathrm{~g}$ of material.

\subsection{Test Conditions}

Three terrestrial landscapes were simulated in the experiment. Non-porous $20 \mathrm{~cm}$ wide $\times 2 \mathrm{~cm}$ deep glass Petri dishes were used as a non-porous control surface. A semi-porous, $20 \times 20 \mathrm{~cm}$ unglazed flat terracotta tile was used to simulate a hard land surface. To represent a porous land surface, the $10 \mathrm{~cm}$ Petri dishes were evenly filled with a $5 \mathrm{~mm}$ thick layer of Australian river sand (Bastion Building Materials, Australia). In between replicates procedures the Petri dishes were fully cleaned and dried.

$5 \mathrm{~mL}$ (3.7346 g) of medium weight crude oil (Chem-supply Pty. Ltd., Gillman, Australia) was carefully applied to the center of the surface of each microcosm. Sorbent materials were pre-weighed to 4 decimal places, applied to the oiled surface, left to adsorb oil for $5 \mathrm{~min}$, then removed from the 
surface and re-weighed (Figure 1). The sorbent-to-surface oil decontamination test was repeated five times for each sorbent type and surface type.

Table 1. Oil spill sorbents used in microcosm experiments.

\begin{tabular}{|c|c|c|}
\hline $\begin{array}{l}\text { Sorbent } \\
\text { Material }\end{array}$ & Description & Origin of Sorbent \\
\hline Polypropylene & $\begin{array}{l}\text { Polypropylene fabric cut into } 2 \mathrm{~cm} \\
\text { wide straps }\end{array}$ & $\begin{array}{l}\text { Global Spill Control Pty. Ltd., } \\
\text { Melbourne, Australia }\end{array}$ \\
\hline Peat moss & Organic peat moss in loose form & $\begin{array}{l}\text { Brunnings Garden Products Pty. Ltd., } \\
\text { Oakleigh South, Australia }\end{array}$ \\
\hline Human hair mat & $\begin{array}{l}\text { Felted product from mixed hair types, } \\
\text { approx. } 10 \mathrm{~mm} \text { thick }\end{array}$ & Matter of Trust, San Francisco, USA \\
\hline Dog fur mat & $\begin{array}{l}\text { Felted product from mixed dog breeds, } \\
\text { approx. } 10 \mathrm{~mm} \text { thick }\end{array}$ & Matter of Trust, San Francisco, USA \\
\hline $\begin{array}{l}\text { Human hair } \\
\text { boom }\end{array}$ & $\begin{array}{l}\text { Prototype hair-filled boom encased } \\
\text { in socking }\end{array}$ & Sustainable Salons, Canberra, Australia \\
\hline Dog fur boom & $\begin{array}{l}\text { Prototype fur-filled boom encased } \\
\text { in socking }\end{array}$ & Sustainable Salons, Canberra, Australia \\
\hline Loose dog fur & Mixed breed loose dog fur & Sustainable Salons, Canberra, Australia \\
\hline Loose human hair & Hair recycled from salon waste & Sustainable Salons, Canberra, Australia \\
\hline
\end{tabular}

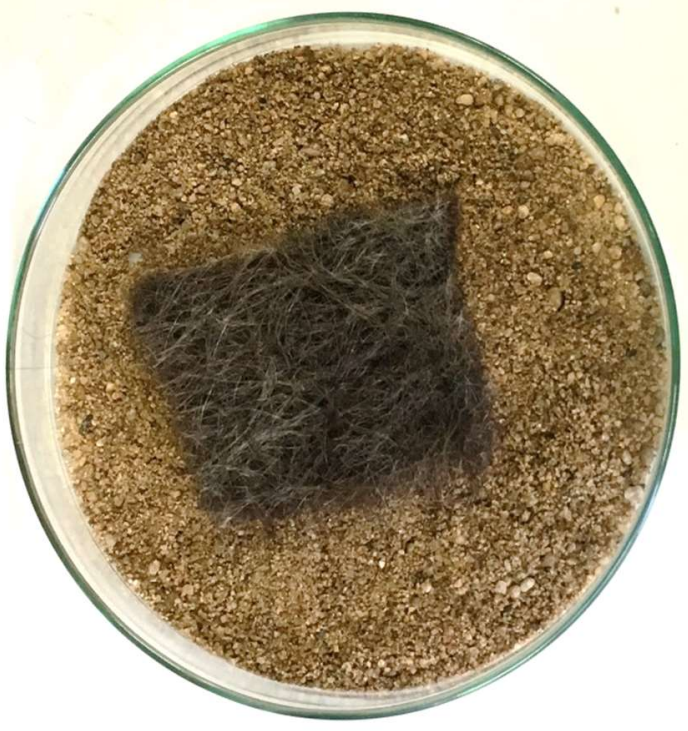

(a)



(b)

Figure 1. Examples of (a) felted dog fur mat and (b) loose human hair deployed on porous, river sand surface.

In instances where the standardized sorbents were not large enough in surface area to cover the whole area of the spill (e.g., tube-shaped oil spill booms), the materials were lightly moved across the spill's entire surface area in a consistent manner, comparable to actions which occur during large-scale clean-ups of oiled environments. Due to extraction complications, peat moss was unable to be measured for oil adsorbency when tested on a sand surface. When attempting to remove the peat moss from the oiled sandy surface for re-weighing, the two substances had merged during the 5-min intervals and it was not feasible to extract the peat moss from the sand. This indicates if peat moss was applied to an oiled sand surface in-situ, it would not be advantageous in crude oil removal. This merging effect was not observed in any of the other sorbent treatments, including loose dog fur and loose human hair. 


\subsection{Statistical Analyses}

We used beta regression [22] to model oil adsorption (response variable as a proportion from 0 to 1 ) as a function of the eight material types (categorical explanatory variable with eight levels) in R [23]. A separate model was used for each of the three surfaces (glass, sand, tile). Analysis of deviance was used to determine the statistical significance of the effect of material on oil adsorption in each model. The lsmeans package [24] was used to determine significant pairwise differences between material types with $P$ value adjustment using the Tukey method for comparing a family of eight estimates. All sorbent treatments with statistically similar performance comparisons are grouped with alphabetical letters within the figures.

\section{Results}

There was an overall significant effect of material type on oil adsorption for all three surfaces; glass $(\chi 2=92.95, \mathrm{DF}=7, p<0.0001)$, sand $(\chi 2=201.03, \mathrm{DF}=7, p<0.0001)$ and tile $(\chi 2=90.71$, $\mathrm{DF}=7, p<0.0001)$. Within the non-porous surface, fur booms and fur mats performed as well as polypropylene at adsorbing higher quantities crude oil (i.e., $>85 \%$ removal), as did loose hair and loose fur $(p \geq 0.05)$ (Figure 2). Hair booms, hair mats and peat moss also adsorbed a similar amount of crude oil from the non-porous surface $(p \geq 0.05)$, adsorbing less than the strongest performing sorbents, but still displaying a $>60 \%$ contaminant removal.



Figure 2. Crude oil adsorbed by different materials on a non-porous, glass surface.

In a semi-porous environment, adsorbency results were more varied across sorbents. Fur mats, fur booms and loose fur had similar increased oil adsorbency to polypropylene of $>75 \%$ contaminant removal $(p>0.05)$, as did hair booms (Figure 3$)$. Loose hair was highly varied in its capacity to consistently adsorb oil from the tile surface. The lower performing sorbents in this scenario were peat moss (i.e., average of $48 \%$ removal) and hair mats (i.e., average of $57 \%$ removal). 


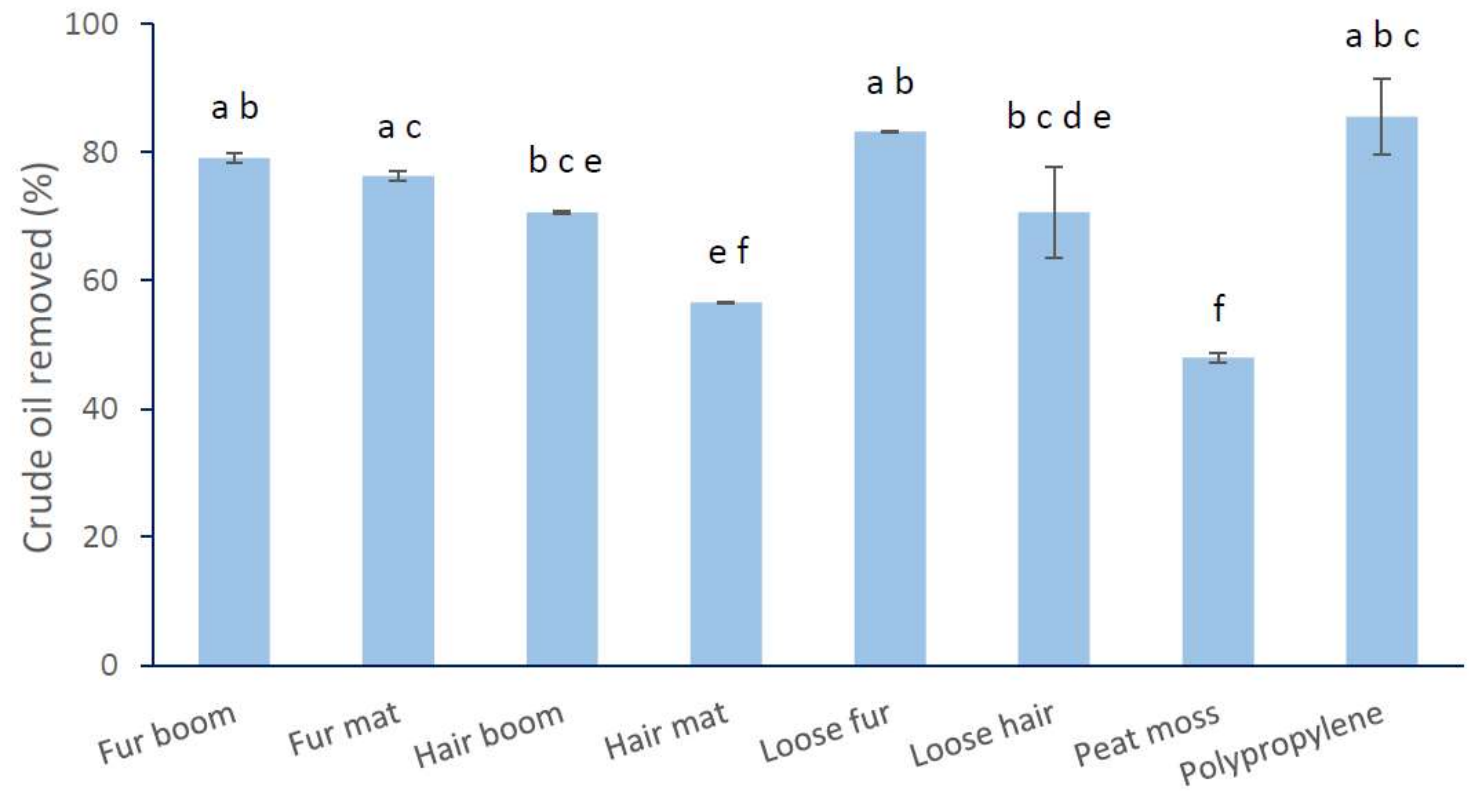

Figure 3. Crude oil adsorbed by different materials on a semi-porous, tile surface.

In a porous, sand environment, polypropylene had the highest crude oil adsorbency (i.e., average of $69 \%$ removal) and performed significantly better than all other sorbent materials $(p<0.001)$. Following this, loose hair and loose fur had similar crude oil adsorbency of 15 to $20 \%$ removal $(p=0.9822)$. All other sorbent materials performed similarly $(p>0.05)$ with less than $5 \%$ crude oil removal from porous sand surfaces (Figure 4).

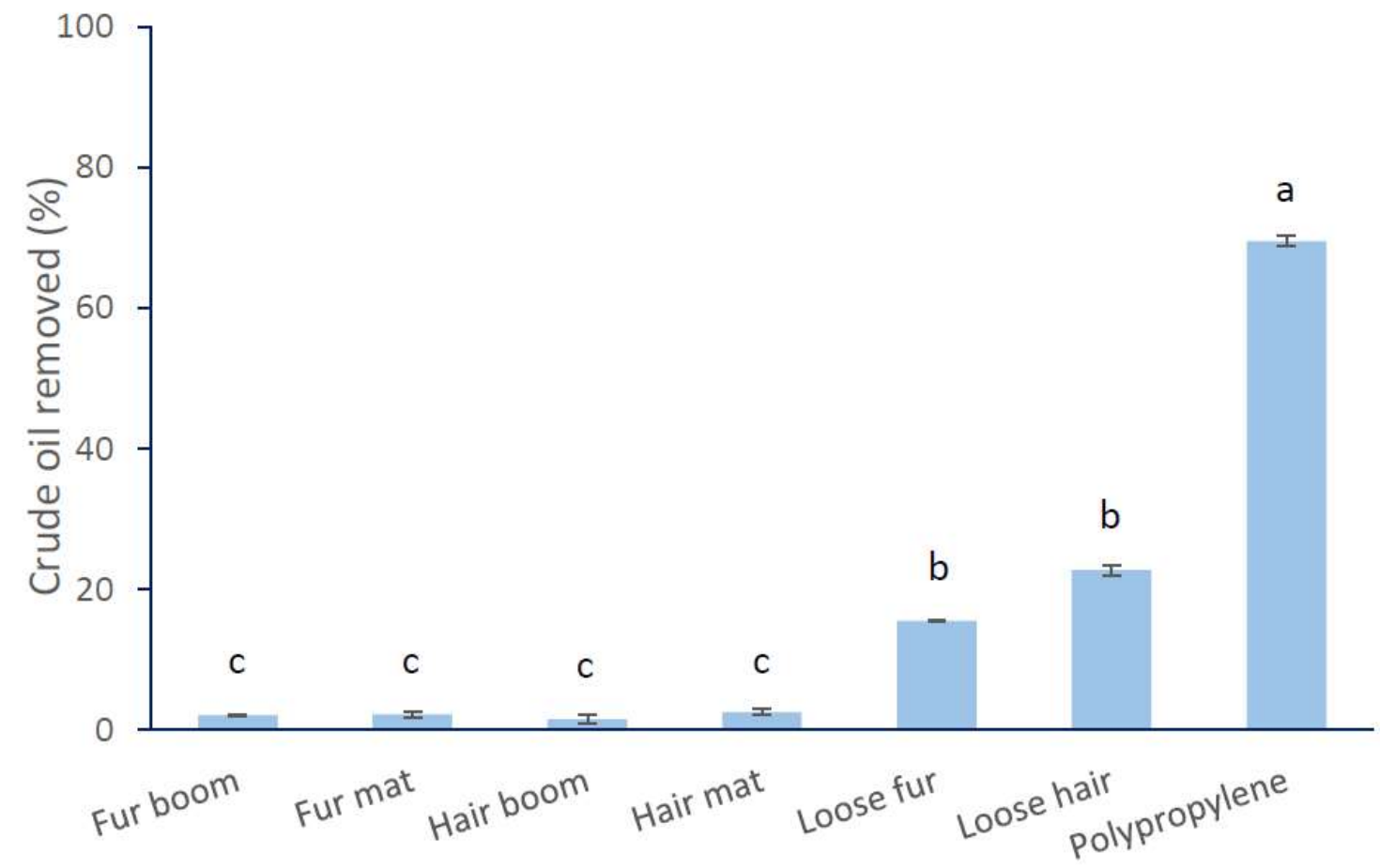

Figure 4. Crude oil adsorbed by different materials on a porous, river sand surface.

\section{Discussion}

Sorbent products are a critically important tool for liquid-form contamination clean-up, including crude oils [18]. For spills occurring on non-porous land surfaces, such as waterproof membrane-sealed 
concretes, there are several equally effective options for sustainable-origin sorbents. Dog fur sorbents in mat and boom forms showed very high oil adsorbance in this type of spill environment, equally effective as commercial polypropylene material in cleaning up spilled crude oil (Figure 2). Given that dog fur sorbent products are a relatively new innovation, and the material is passively and continually generated by the dog grooming industry and donated from domestic activities, this is a particularly note-worthy finding for a sustainable sorbent option. For loose-form sorbent materials, human hair was also highly effective at adsorbing spilled crude oil. Loose-form hair used in this study had no special pre-treatments (i.e., unwashed salon waste), which indicates this material also has potential application for up-scaling in a cost-effective manner, depending on deployment and collection methods. Loose-form products are likely to be the hardest to recover in a real-world disaster from a logistical perspective, as it would be difficult to retrieve disparate particles once spread across a larger outdoor surface, and winds and other weather processes are likely to shift the materials.

More differentiation between sorbent effectiveness can be seen when applied to decontaminate a semi-porous land surface, similar to concrete walking footpaths and bitumen road surfaces (Figure 3). Dog fur products were equally effective at adsorbing crude oil regardless of the mode of deployment (i.e., felted mat, encased boom, loose) and the oil decontamination was found to be very consistent within sorbent products, with little variation across replicates. A future avenue for scientific investigation may be to explore the fur clippings of different breeds of dog to determine whether fur texture and length promote crude oil adsorbency, although preferential fur sorting would add more complexity to the creation of mat and boom oil spill products from waste streams and may not yield significant decontamination benefits as a trade-off.

Stark difference in the oil adsorbency efficacy between products can be seen on river sand, with performance decreasing dramatically overall for all sorbent products in this environment (Figure 4). Polypropylene was markedly better at adsorbing crude oil compared to all other products, followed by loose hair and loose dog fur. It appears oil adheres more strongly to polypropylene fabric over a sand matrix, whereas the sustainable-origin products were less able to adsorb the oil from the sand, once spilled. This indicates sandy shorelines are particularly vulnerable to prolonged crude oil contamination, once floating oils reach land edges, and additionally crude oil run-off from larger, land-based spills are likely to worsen in remediation difficulty once they reach sands and sediments. Particular importance should be placed on decontaminating oils on water surfaces and harder terrestrial surfaces to avoid this scenario. Furthermore, investigation into the physical characteristics of polypropylene fabric which appears to make this a good crude oil sorbent for sand surfaces should be explored.

Peat moss did not remove spilled oil as effectively as sustainable-origin or polypropylene products on semi-porous environments, being one of the lowest-performing products for non-porous land surfaces, and was found to be entirely unusable on a sand surface in raw form. Peat moss is a valuable organic substance that is generated by peat bogs. Given the limited availability of peat worldwide, the need for peat to be destructively harvested from wetlands, and its relatively poor performance within this experiment compared to other products, it is recommended this sorbent is not used preferentially to decontaminate crude oil spills in this context.

In terms of ease of application and removal, felted mats and encased booms represented the easiest method for deployment and recovery when compared to loose-form products. Visibly fewer fragments and residues were left in the microcosms by the non-loose-form materials. A secondary benefit to felted mats is they do not have any synthetic casings compared to booms and are therefore more likely to be easier to process for sorbent re-use, as well as composting, compared to products with synthetic external fabrics. Due to the stronger structural integrity of felted material, one future application for felt-type sorbent is to decontaminate flowing polluted water, similar to existing membrane technology. Further research investigating the oil saturation capacity of these new sorbent materials, as well as the ease of crude oil extraction and recovery, re-use capacity of the sorbents, sorbent storage lifespan and natural degradability as well as compositing ability and safety will further illuminate the potential for 
sustainable-origin sorbents to become part of large-scale decontamination protocols for land managers at a local-level as well as national disaster-response agencies.

Author Contributions: Conceptualization, M.L.M.; dta curation, M.L.M. and S.M.P.; formal analysis, B.R.M.; investigation, M.L.M. and S.M.P.; supervision, M.L.M. and B.R.M.; writing-original draft, M.L.M. and S.M.P.; writing-review and editing, M.L.M. and B.R.M. All authors have read and agreed to the published version of the manuscript.

Funding: This research received no external funding.

Acknowledgments: The research team thanks Lisa Craig Gautier, Founder of Matter of Trust, for donating felted dog fur and human hair mats used in this research, as well as providing information on sorbent collection and creation pathways. We wish to thank Betty Cheng, Matter of Trust, for research project assistance and logistical support. We would like to thank Ewelina Soroko and Paul Frasca, Co-founders of Sustainable Salons, for donating prototype dog fur and hair booms as well as loose-form hair and fur used in this research. We wish to acknowledge the scientific contributions of Phil McCrory in the original creation and application of hair sorbents for oil spill disasters.

Conflicts of Interest: The authors declare no conflict of interest.

\section{References}

1. Rogowska, J.; Namieśnik, J. Environmental implications of oil spills from shipping accidents. Rev. Environ. Contam. Toxicol. 2010, 206, 95-114. [PubMed]

2. Allan, S.E.; Smith, B.W.; Anderson, K.A. Impact of the Deepwater Horizon oil spill on bioavailable polycyclic aromatic hydrocarbons in Gulf of Mexico coastal waters. Environ. Sci. Technol. 2012, 46, 2033-2039. [CrossRef] [PubMed]

3. Shailaja, M.; D'Silva, C. Evaluation of impact of PAH on a tropical fish, Oreochromis mossambicus using multiple biomarkers. Chemosphere 2003, 53, 835-841. [CrossRef]

4. Achten, C.; Hofmann, T. Native polycyclic aromatic hydrocarbons (PAH) in coals-A hardly recognized source of environmental contamination. Sci. Total Environ. 2009, 407, 2461-2473. [CrossRef] [PubMed]

5. Loughlin, T.R. Marine Mammals and the Exxon Valdez. Science 1994, 267, 2013-2014.

6. Fasca, H.; de Castilho, L.; de Castilho, J.; Pasqualino, I.; Alvarez, V.; de Azevedo Jurelevicius, D.; Seldin, L. Response of marine bacteria to oil contamination and to high pressure and low temperature deep sea conditions. Microbiol. Open 2017, 7, e00550. [CrossRef] [PubMed]

7. Tissier, F.; Dussauze, M.; Lefloch, N.; Theron, M.; Lemaire, P.; Floch, S.P.L.; Pichavant Rafini, K. Effect of dispersed crude oil on cardiac function in seabass Dicentrarchus labrax. Chemosphere 2015, 132, 192-198. [CrossRef] [PubMed]

8. Stefansson, E.S.; Langdon, C.J.; Pargee, S.M.; Blunt, S.M.; Gage, S.J.; Stubblefield, W.A. Acute effects of non-weathered and weathered crude oil and dispersant associated with the Deepwater Horizon incident on the development of marine bivalve and echinoderm larvae. Environ. Toxicol. Chem. 2016, 35, 2016-2028. [CrossRef] [PubMed]

9. Suchanek, T.H. Oil impacts on marine invertebrate populations and communities. Am. Zool. 1993, 33, 510-523. [CrossRef]

10. Garshelis, D.; Johnson, C. Prolonged recovery of sea otters from the Exxon Valdez oil spill? A re-examination of the evidence. Mar. Pollut. Bull. 2013, 71,7-19. [CrossRef] [PubMed]

11. Bartha, R.; Bosser, I. The treatment and disposal of petroleum refinery wastes. In Petroleum Microbiology; Macmillan: New York, NY, USA, 1984; pp. 553-577.

12. Oil Spill Prevention + Response (2018) Cleanup, Land. 2018. Available online: http://www.oilspillprevention. org/oil-spill-cleanup/land-oil-spill-cleanup (accessed on 8 June 2020).

13. Hospital, A.; Stronach, J.A.; McCarthy, M.W.; Johncox, M. Spill response evaluation using an oil spill model. Aquat. Proc. 2015, 3, 2-14. [CrossRef]

14. Allen, A.; Ferek, R. Advantages and Disadvantages of Burning Spilled Oil. Int. Oil Spill Conf. Proc. 1993, 1993, 765-772. [CrossRef]

15. Atlas, R. Petroleum biodegradation and oil spill bioremediation. Mar. Pollut. Bull. 1995, 31, 178-182. [CrossRef] 
16. Fingas, M.F.; Fingas, M. In-Situ Burning, Oil Spill Science and Technology. Elsevier Sci. Technol. 2010, Part VII, 736.

17. Pagnucco, R.; Phillips, M. Comparative effectiveness of natural by-products and synthetic sorbents in oil spill booms. J. Environ. Manag. 2018, 225, 10-16. [CrossRef] [PubMed]

18. Adebajo, M.O.; Frost, R.L.; Kloprogge, J.T.; Carmody, O.; Kokot, S. Porous materials for oil spill cleanup: A review of synthesis and absorbing properties. J. Porous Mater. 2003, 10, 159-170. [CrossRef]

19. Al-Majed, A.A.; Adebayo, A.R.; Hossain, M.E. A sustainable approach to controlling oil spills. J. Environ. Manag. 2012, 113, 213-227. [CrossRef] [PubMed]

20. Ifelebuegu, A.O.; Nguyen, T.V.A.; Ukotije-Ikwut, P.; Momoh, Z. Liquid-phase sorption characteristics of human hair as a natural oil spill sorbent. J. Environ. Chem. Eng. 2015, 3, 938-943. [CrossRef]

21. Worthington, M.; Shearer, C.; Esdaile, L.; Campbell, J.; Gibson, C.; Legg, S.; Yin, Y.; Lundquist, N.; Gascooke, J.; Albuquerque, I.; et al. Sustainable Polymers: Sustainable Polysulfides for Oil Spill Remediation: Repurposing Industrial Waste for Environmental Benefit. Adv. Sustain. Syst. 2018, 2, 6.

22. Mangiafico, S.S. Summary and Analysis of Extension Program Evaluation in R, Version 1.18.1; Rutgers Cooperative Extension: New Brunswick, NJ, USA, 2016.

23. R Core Team. R: A Language and Environment for Statistical Computing; R Foundation for Statistical Computing: Vienna, Austria, 2019.

24. Lenth, R.V. Least-Squares Means: The R Package lsmeans. J. Stat. Softw. 2016, 69, 1-33. [CrossRef]

(C) 2020 by the authors. Licensee MDPI, Basel, Switzerland. This article is an open access article distributed under the terms and conditions of the Creative Commons Attribution (CC BY) license (http://creativecommons.org/licenses/by/4.0/). 